Military Technical College Kobry El-Kobbah, Cairo, Egypt

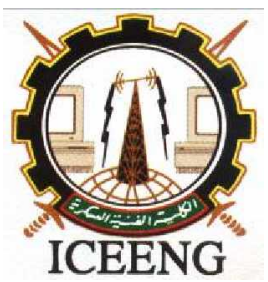

\author{
$6^{\text {th }}$ International Conference \\ on Electrical Engineering \\ ICEENG 2008
}

\title{
Design and development of the middle-frequency isolation transformer for the high-voltage DC/DC converter
}

By
D. Vinnikov*
T. Lehtla*
R. Strzelecki ${ }^{* *}$
I. Galkin ${ }^{* * *}$

\section{Abstract:}

Among the performance requirements of railway equipment applied to the $3.0 \mathrm{kV} \mathrm{DC}$ catenary-fed auxiliary power supplies (APS), the most significant one is compliance with electric safety requirements. It provides the specific feature for the power circuit topology of APS converter, requiring an isolation transformer to decouple input and output sides (with the isolation voltage at least $12 \mathrm{kV}$ ). Since the isolation transformer in switching-mode power supplies contributes about $25 \ldots 30 \%$ of the overall volume and more than $30 \%$ of the overall weight, the design of a compact and lightweight system will be a great challenge for the designer [1]. This paper is mainly addressed to some specific design issues that are encountered during the development of isolation transformers for the rolling stock APS. For the middle-frequency $(500 \ldots 3000 \mathrm{~Hz})$ highpower transformers, the optimal transformer design rule of the copper and core loss equalization will not work. Main attention here must be paid to select proper material for the magnetic core and to define an optimal operating flux density to minimize the dimensions and to improve operability and efficiency of the transformer, respectively. For the isolation transformers designed for the APS converters with high input voltage and load variations, threat related to magnetic core saturation caused by transient conditions should be considered. These and some other specific design issues (minimization of leakage inductance and parasitic capacitances, high-voltage isolation, etc.) make the design of such devices very challenging.

\section{Keywords:}

Isolated DC/DC converters, auxiliary power supplies for rail vehicles, transformers

\footnotetext{
* Tallinn University of Technology, Tallinn, Estonia

** Gdynia Maritime Academy, Gdynia, Poland

*** Riga Technical University, Riga, Latvia
} 


\section{Introduction:}

In 2007 during the $\mathrm{R} \& \mathrm{D}$ project an experimental high-voltage half-bridge isolated DC/DC converter based on innovative high-voltage (HV) $6.5 \mathrm{kV}$ IGBT transistors was developed in the Department of Electrical Drives and Power Electronics of Tallinn University of Technology. The layout of the experimental converter power scheme and its general specifications are presented in Fig. 1 [2].

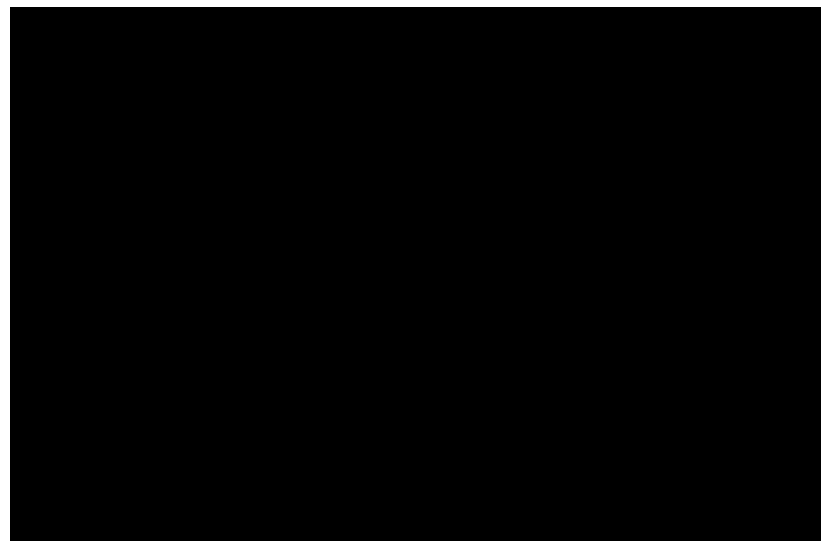

(a)

\begin{tabular}{l|l} 
Parameter & Value \\
\hline $\begin{array}{l}\text { Continuous minimal input } \\
\text { voltage } \mathrm{U}_{\text {in(min) }}\end{array}$ & $2400 \mathrm{VDC}$ \\
\hline $\begin{array}{l}\text { Continuous maximal input } \\
\text { voltage } \mathrm{U}_{\text {in(max) }}\end{array}$ & $4000 \mathrm{VDC}$ \\
\hline Nominal output voltage $\mathrm{U}_{\mathrm{O}}$ & $350 \mathrm{VDC}$ \\
\hline Rated output power $\mathrm{P}_{\mathrm{O}}$ & $50 \mathrm{~kW}$ \\
\hline $\begin{array}{l}\text { Primary inverter switches } \\
(\mathrm{TT}, \mathrm{TB})\end{array}$ & $\begin{array}{l}2 \times \mathrm{IGBT} 6.5 \mathrm{kV} 200 \mathrm{~A} \\
(\mathrm{EUPECFZ200R65KF1)}\end{array}$ \\
\hline $\begin{array}{l}\text { Primary inverter switching } \\
\text { frequency } \mathrm{f}_{\mathrm{sw}}\end{array}$ & $1000 \mathrm{~Hz}$
\end{tabular}

Figure (1): Experimental high-voltage half-bridge isolated DC/DC converter topology $(a)$ and the general specifications of the experimental converter $(b)$

HV IGBT implementation is attractive since it provides an excellent opportunity to simplify a power scheme, avoiding the series connection of conventional IGBTs used to achieve proper voltage blocking capability. Using a single $6.5 \mathrm{kV}$ IGBT module instead of several series-connected IGBTs helps to achieve a more reliable, efficient, compact and lightweight design than ever. However, the limited switching dynamics of $\mathrm{HV}$ IGBTs (switching frequency range is $500 \ldots 3000 \mathrm{~Hz}$ ) imposes some challenges in the converter design, especially in terms of magnetics. First of all, the isolation transformers and output filter inductors in such applications can be regarded as the bulkiest components in the whole converter stack. For such middle-frequency (MF) operation range, the highest possible values of permeability $\left(\mu_{\mathrm{H}}\right)$ and saturation magnetic induction $\left(\mathrm{B}_{\max }\right)$ of the isolation transformer magnetic core material is essential, because it gives an additional advantage for weight-space optimization of the transformer. Other possible problems are connected to the behavior of the isolation transformer in transient conditions, i.e. during the rapid change of the input voltage or/and load within the defined ranges, where the threat of transformer saturation is arising. Finally, the designer must provide the most cost-effective solution at high efficiency to meet the end-user requirements. 


\section{Isolation Transformer Operating Parameters:}

The input side of the experimental converter is directly connected to the traction supply grid with the voltage tolerances from 2400 VDC up to 4000 VDC (see Fig. 1). Due to the capacitors $\mathrm{C} 1$ and $\mathrm{C} 2$ providing a mid-voltage point, the isolation transformer during the operation sees a positive and negative voltage with the amplitude value $\mathrm{U}_{\text {Ia }}$ of only half the input voltage (see Fig. 2). This results in twice the desired peak flux value of the core, because the transformer core is operated in the first and third quadrant of the B-H loop and experiences twice the flux excursion of a similar forward converter core. This is an advantage of the half-bridge topology over the double-ended forward topologies, where the half-bridge primary transformer winding has half the turns for the same input voltage and power.

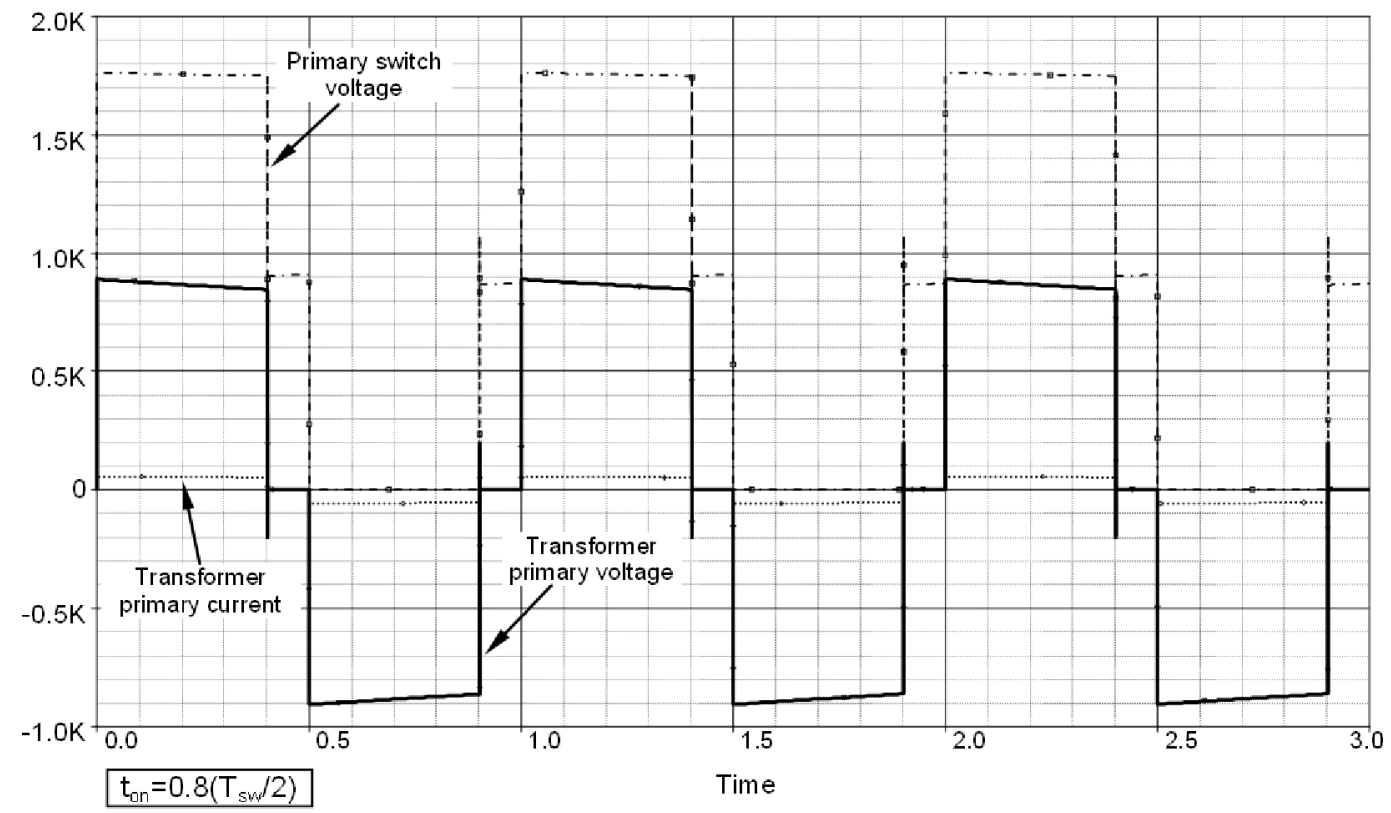

Figure (2): Simulated isolation transformer primary voltage and current waveforms

The most demanding operation point is at the minimum input voltage and at the rated load conditions (i.e., maximum duty cycle operation). It is essential to prevent even short-time simultaneous conduction of TT and TB switches in these demanding conditions - it leads to the short circuit across the supply voltage and to the destruction of the converter. It means that the maximum on-state time $t_{\text {on(max) }}$ of each switch in the half-bridge must be set at $80 \%$ of a half-period $\left(\mathrm{T}_{\mathrm{sw}}\right)$ to ensure that this does not happen. Pulse width at the maximum input voltage is minimal and may be determined as

$\mathrm{t}_{\mathrm{on}(\min )}=\frac{\mathrm{U}_{\mathrm{in}(\min )}}{\mathrm{U}_{\mathrm{in}(\max )}} \mathrm{t}_{\mathrm{on}(\max )}=\frac{2400}{4000} \mathrm{t}_{\mathrm{on}(\max )}=0.44\left(\frac{\mathrm{T}_{\mathrm{sw}}}{2}\right)$. 
Thus the isolation transformer must operate normally in the wide supply voltage range $(1100 \ldots 2000 \mathrm{~V})$ with the constantly changing duty cycle. Simulated waveforms of isolation transformer primary voltage in the boundary operating points are presented in Fig. 3.

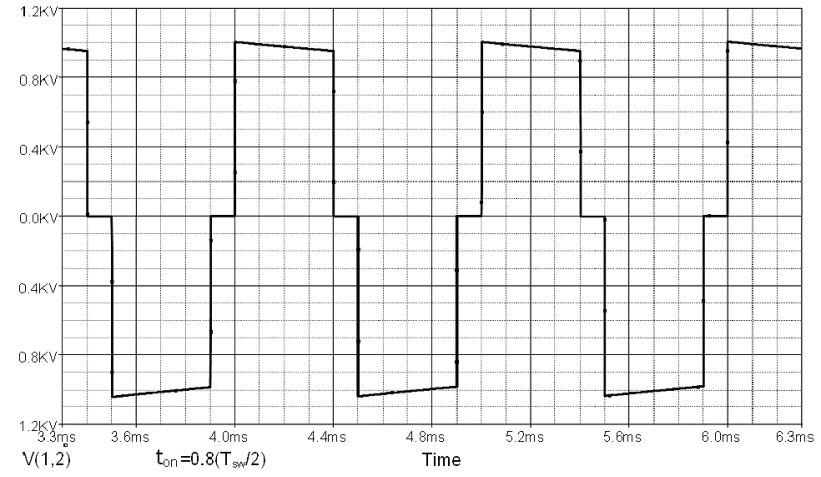

(a)

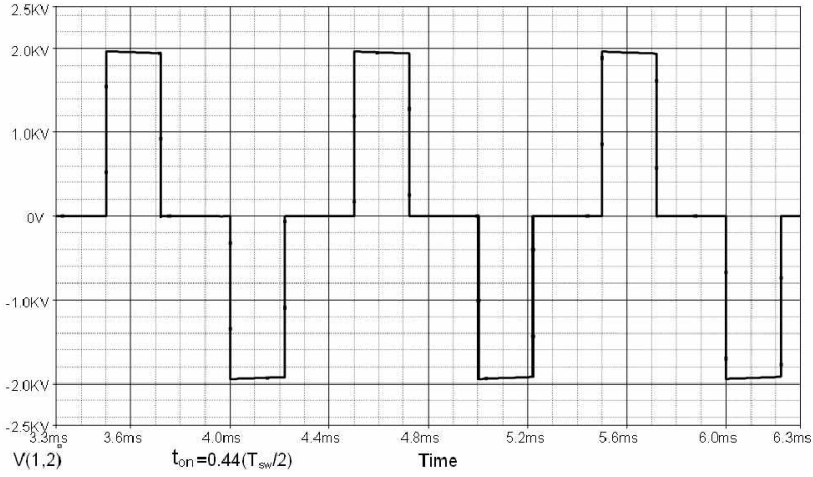

(b)

Figure (3): Isolation transformer primary voltage waveforms for maximum (a) and minimum (b) duty cycle operation

For the described application, the converter output voltage must be carefully regulated to $350 \mathrm{~V}$ DC despite the voltage fluctuations on the input side. Considering the voltage drop in the output rectifier and filter assembly $\left(\mathrm{U}_{\mathrm{drf}}\right)$, the required amplitude value of the transformer secondary voltage $\mathrm{U}_{\text {II }}$ in the most demanding applications (i.e. minimum input voltage and the rated load conditions - operation with the maximum duty cycle) can be estimated as

$$
\mathrm{U}_{\text {IIa }}=\mathrm{U}_{\mathrm{O}} \cdot \frac{\mathrm{T}_{\mathrm{sw}}}{2 \cdot \mathrm{t}_{\mathrm{on}}}+\mathrm{U}_{\mathrm{drf}} .
$$

\section{Specific Problem Areas and Design Considerations:}

For such low operating frequency (i.e., $500 \ldots 3000 \mathrm{~Hz}$ ) the higher possible values of permeability $\left(\mu_{\mathrm{H}}\right)$ and saturation magnetic induction $\left(\mathrm{B}_{\max }\right)$ of the magnetic core material is essential, because it gives an additional advantage of transformer weight-space optimization. Table 1 provides a comparison of different soft magnetic materials. The basic field of choice in such operation frequency range is iron steel and Permalloy. However, despite its good magnetic properties the latter has a drawback of increased magnetostriction. Another drawback of Permalloy type alloys is associated with their softness in that flat particles are liable to deform by stresses induced during milling to form a coating composition, also resulting in a loss of magnetic properties. Ferrites are 
not considered for such high-power low-frequency operation because of their relatively low permeability and saturation magnetic induction.

Table (1): Magnetic properties of some soft magnetic materials

\begin{tabular}{|l|c|c|c||}
\hline & $\mathbf{B}_{\mathbf{M A X}}, \mathbf{T}$ & $\boldsymbol{\mu}_{\mathbf{H}}$ & $\boldsymbol{\mu}_{\mathbf{M A X}}$ \\
\hline Permalloy & $0.70 \ldots 0.75$ & $14000 \ldots 50000$ & $60000 \ldots 300000$ \\
\hline Silicon steel & 2 & $200 \ldots 600$ & $3000 \ldots 8000$ \\
\hline Ferrites & $0.18 \ldots 0.40$ & $100 \ldots 6000$ & $3000 \ldots 10000$ \\
\hline Iron & 2.16 & 250 & 7000 \\
\hline GAMMAMET $^{\circledR}$ & $0.8 \ldots 1.12$ & $7000 \ldots 20000$ & $40000 \ldots 600000$ \\
\hline
\end{tabular}

For this project, advanced GAMMAMET ${ }^{\circledR}$ toroidal magnetic cores made from $25 \mu \mathrm{m}$ thick ribbon of soft magnetic nanocrystalline alloy on Fe-basis were investigated. The real advantages of the selected toroidal magnetic cores Gm14DC are their high initial permeability and very low core losses [3], [4]. Typical specifications of Gm14DC magnetic cores are presented in Fig. 4.

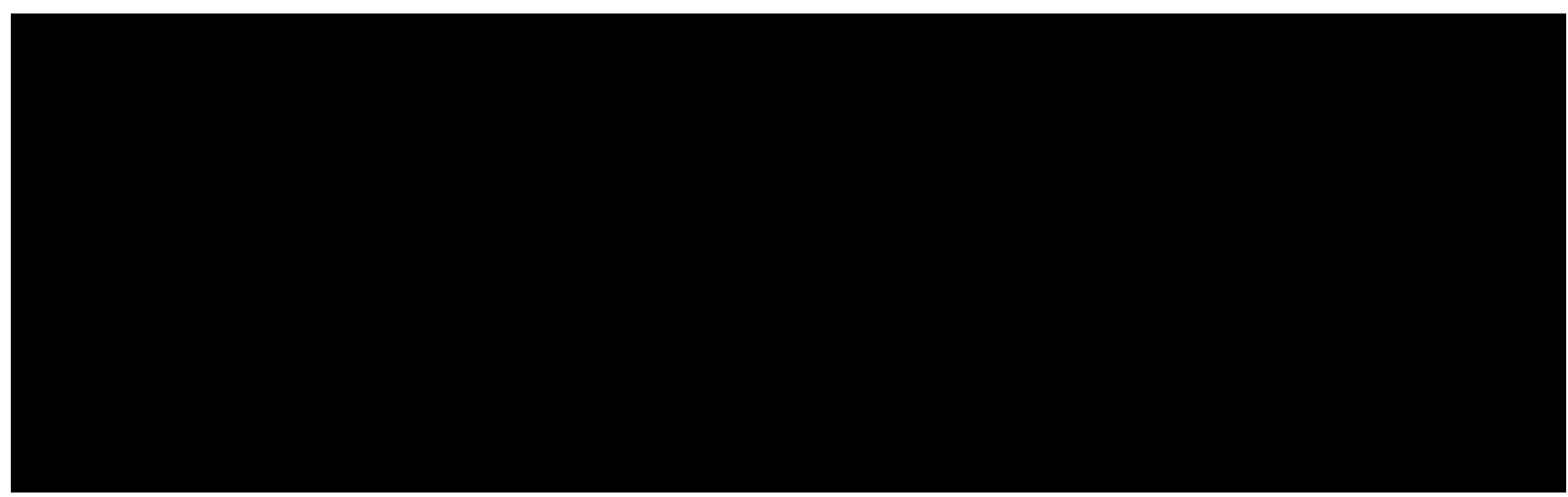

Figure (4): $B-H$ loop (a) and typical magnetic and physical properties (b) of GAMMAMET ${ }^{\circledR} 14$ DC magnetic cores

In general, the design approach for the half-bridge converter isolation transformer is relatively simple. The primary winding is used for both half-cycles of operation (using both quadrants of the B-H loop, see Fig. 4, a), providing extremely good transformer core and copper utilization. The pulse transformer core volume $\mathrm{V}_{\mathrm{m}}$ should be selected to meet the power requirements and temperature rise for the selected operating frequency:

$\mathrm{V}_{\mathrm{m}}=1.5 \sqrt{\frac{\mathrm{A} \cdot \mathrm{k}_{\mathrm{ADD}} \cdot \mathrm{k}_{\mathrm{T}}}{\mathrm{k}_{\mathrm{U}}}} \cdot \frac{\mathrm{P}}{\mathrm{f}^{\frac{1}{4}} \cdot \Delta \mathrm{T}}$,

where $\mathrm{P}$ is the transformer rated power, $\mathrm{k}_{\mathrm{T}}$ is the temperature coefficient of winding resistance, $\mathrm{k}_{\mathrm{U}}$ is the window utilization factor, $\Delta \mathrm{T}$ is transformer temperature rise and $\mathrm{A}$ 
is the specific core loss factor:

$$
A=P_{D(\text { core })}^{\prime} \cdot f^{\alpha-\frac{3}{2}} \cdot B_{m}^{\beta-2} \cdot\left(f^{*}\right)^{-\alpha} \cdot\left(B_{m}^{*}\right)^{-\beta} \text {. }
$$

Figure 5 gives an overview of specific core losses and minimal required core volume vs. operating flux density for the different operating frequencies for the $50 \mathrm{~kW}$ isolation transformer with GAMMAMET ${ }^{\circledR} 14 \mathrm{DC}$ toroidal core.

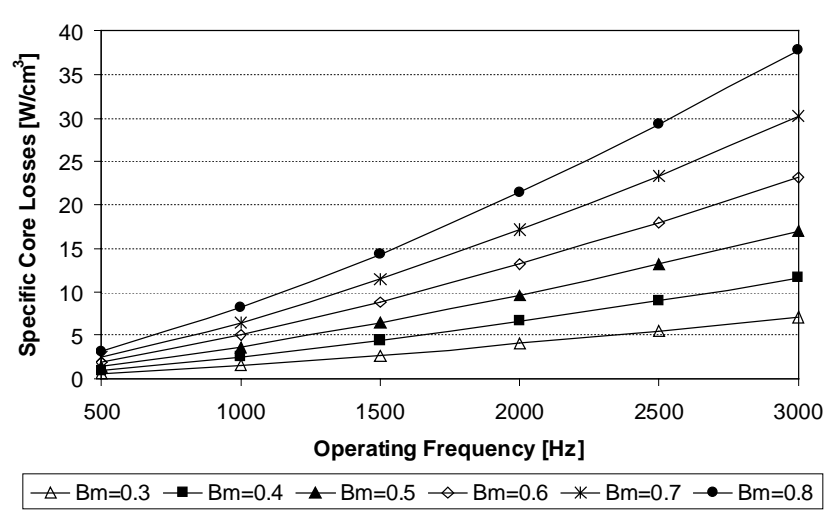

(a)

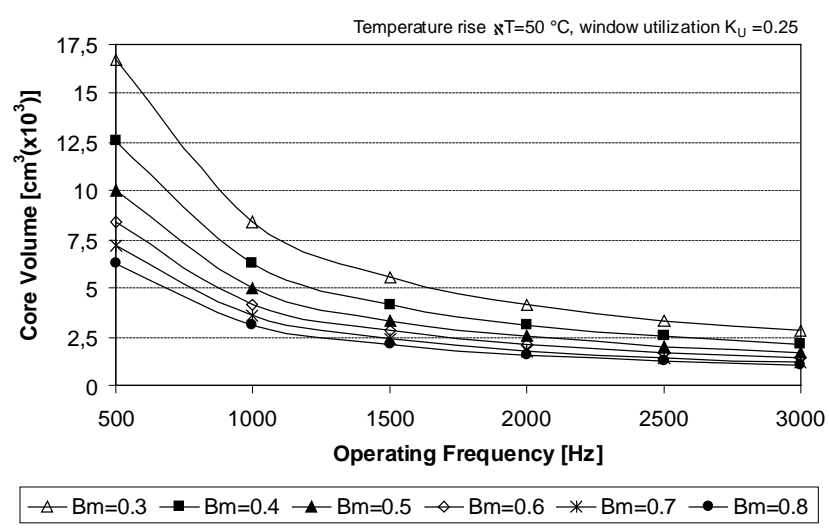

(b)

Figure (5). Specific core losses (a) and minimal required core volume (b) vs. operating flux density as a function of operating frequency for the $50 \mathrm{~kW}$ isolation transformer with GAMMAMET ${ }^{\circledR}$ 14DC magnetic core

In the isolated DC/DC converters with a wide input voltage and load variations with the increase of input voltage, the on-state time (pulse width) of the switch will normally decrease in the same ratio to maintain the output voltage constant. Under these conditions the peak flux density of the isolation transformer core remains constant at some certain designed value. However, under several transient conditions (rapid load changes, unstable supply from the contact line, etc.), it is possible for the pulse width to increase to its maximum irrespective of the input voltage. This can occur at maximum input voltage. The increase in the flux density at maximum input voltage will follow the same ratio as the increase in voltage. The operating flux density would abruptly increase to $30 . .50 \%$ from the predefined value, thus overcoming the saturation limit. For the saturation prevention, the isolation transformer for such applications must be designed for the lower flux level. However, such conservative design approach results in a lowerefficiency transformer, because more turns are required (see Fig. 5, a). Another issue to be taken into account during the design procedure is that the operating flux excursion $\Delta \mathrm{B}$ in a non-ideal case may not always be $2 \mathrm{~B}$ [5]. Thus, during the converter turn-on the operation point of the core flux density is normally lies between two remanent flux values. Hence, for the first half-cycle, the flux doubling effect could occur, i.e. a flux change of 2B may take the core into saturation. The isolation transformer core 
saturation will also occur in a half-bridge converter due to the mid-voltage point shift, which can be caused by the input capacitor mismatch. The solution to these problems is to reduce the operating flux range $\Delta \mathrm{B}$ and use more turns in the primary winding in order to provide a good working margin. The margin required depends on how well the above effects have been controlled.

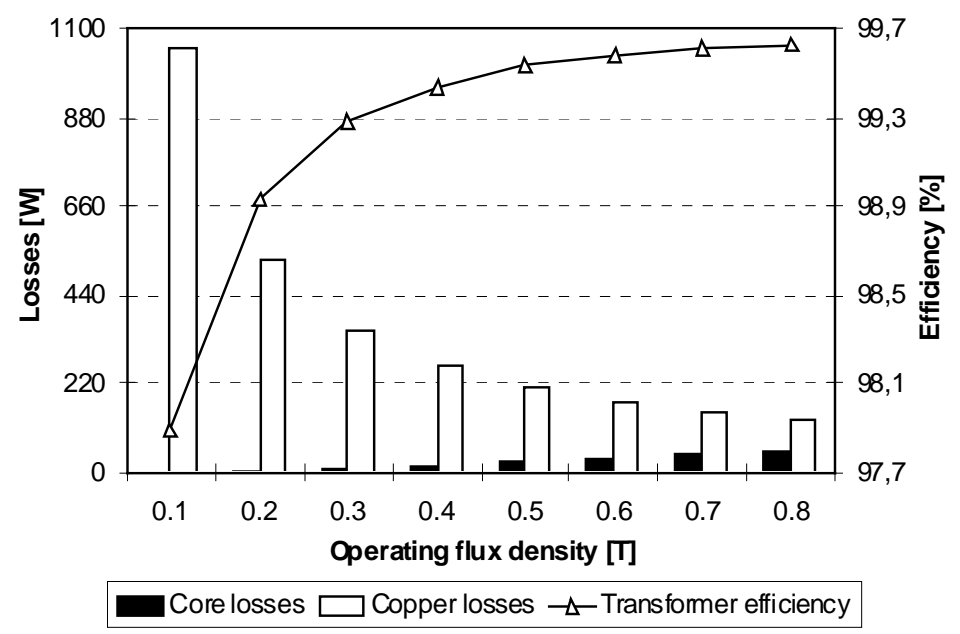

Figure (6): $1 \mathrm{kHz}$ isolation transformer losses and efficiency as a function of operating flux density

\section{Experimental Verification:}

During the project the experimental toroidal transformer based on above presented approach was assembled and tested. General view of the developed transformer is presented in Fig. 7.
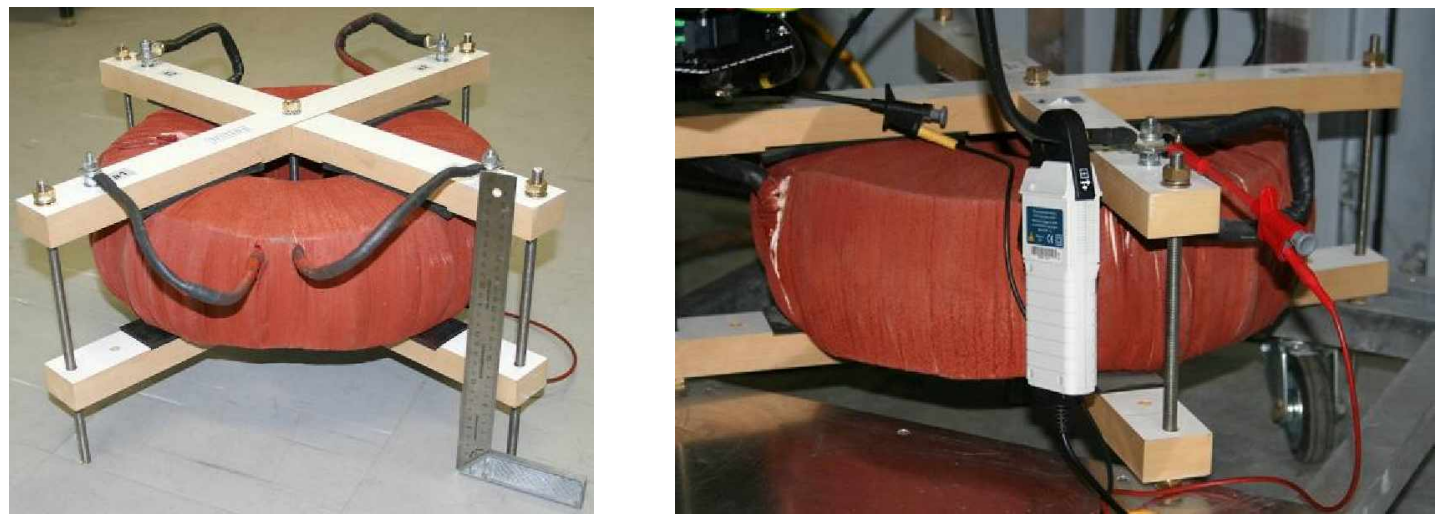

Figure (7): General view of the developed $50 \mathrm{~kW} 1 \mathrm{kHz}$ isolation transformer Measured waveforms of isolation transformer primary voltage in the boundary operating points are presented in Fig. 8. 


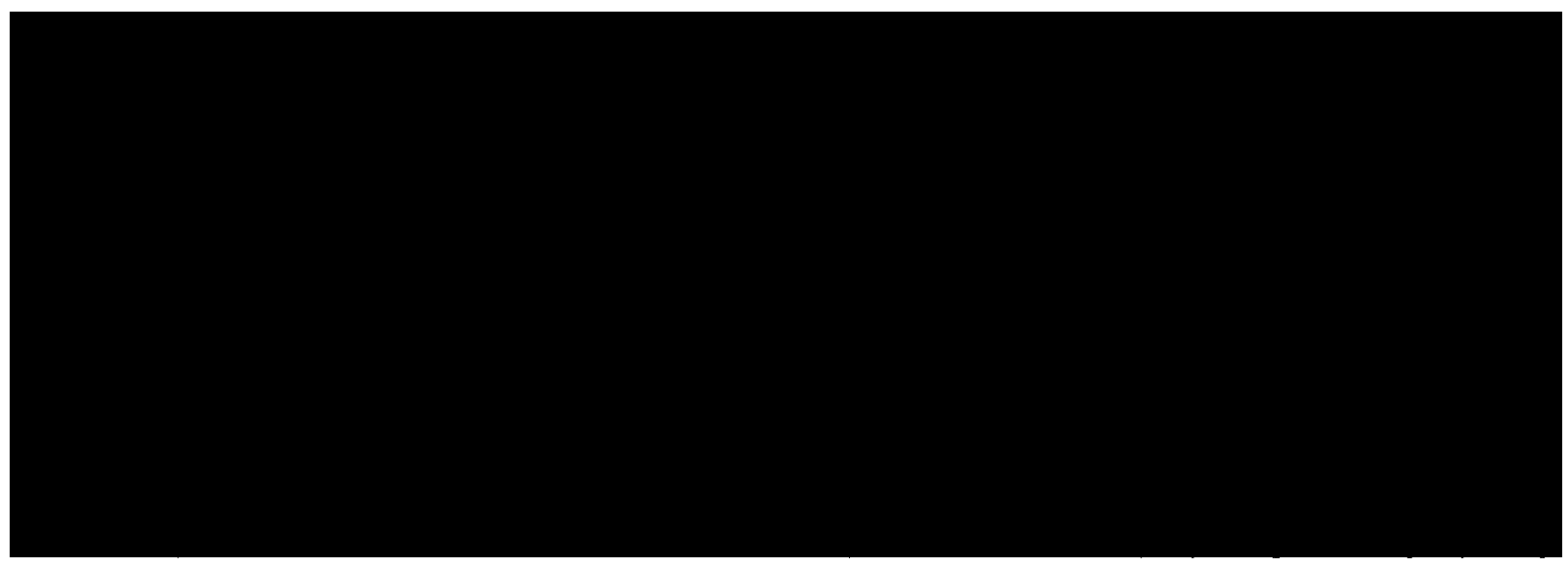

Figure (8): Isolation transformer supply voltage measured waveforms for maximum (a) and minimum (b) duty cycle operation

\section{Conclusions:}

Considering the above assumptions, the design of middle- or high-frequency isolation transformers for the high-power high-voltage converters is always a tradeoff between operability, flexibility and efficiency. In the current project the average core power dissipation for the $1 \mathrm{kHz} 50 \mathrm{~kW}$ isolation transformer is about $35 \mathrm{~W}$ with the assumed maximum flux density of $0.6 \mathrm{~T}$. Estimated winding losses for this particular design (special litz wire was used in both windings) are not higher than $190 \mathrm{~W}$.

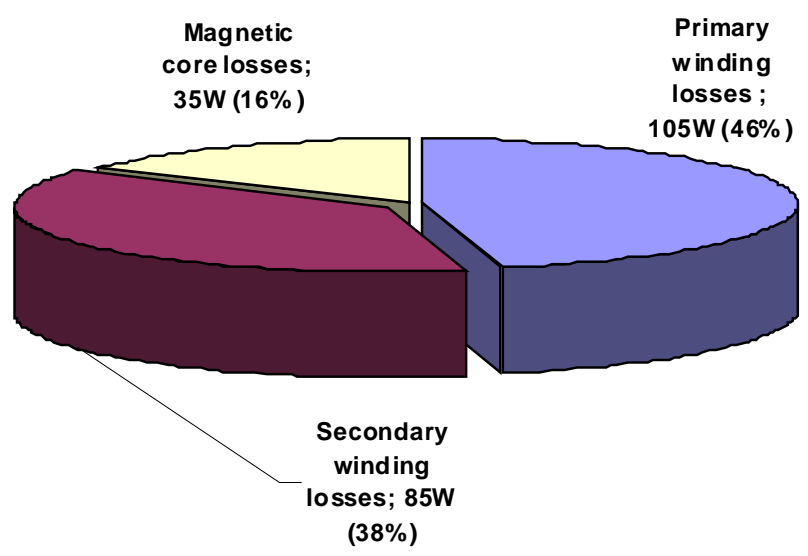

Figure (9): Power loss distribution in the developed isolation transformer

With the total power dissipation of $225 \mathrm{~W}$ (Fig. 9), the efficiency of the developed $1 \mathrm{kHz} 50 \mathrm{~kW}$ transformer is $99.5 \%$, which is a quite good result for such a demanding application. 


\section{Acknowledgement:}

Authors thank Estonian Science Foundation (Grant No. 7572) for financial support of this study.

\section{References:}

[1] R. Petkov, Optimum design of a high-power, high-frequency transformer, IEEE Transactions on Power Electronics, vol. 11, issue 1, pp. 33-42, 1996.

[2] T. Jalakas, D. Vinnikov, J. Laugis, Development of 50-kW Isolated DC/DC Converter with High-Voltage IGBTs, in Proc. of IEEE Compatibility in Power Electronics Conference CPE '07, pp.1-6, 2007.

[3] Y. N. Starodubtsev, V. I. Keilin, V. Y. Belozerov, Cores of Fast-Quenched GAMMAMET alloys with a linear magnetization curve, Russian Electrical Engineering, ISSN1068-3712, ETATS-UNIS, 1993.

[4] Magnetic Properties of Tape Wound Encapsulated Cores GAMMAMET ${ }^{\circledR} 14 D C$, GAMMAMET Research \& Production Enterprise, 2007.

[5] K. H. Billings, Switchmode Power Supply Handbook. McGraw-Hill, 1989.

[6] J.C. Fothergill, P.W. Devine, P.W. Lefley, A novel prototype design for a transformer for high voltage, high frequency, high power use, IEEE Transactions on Power Delivery, vol. 16, issue 1, pp. 89-98, 2001.

[7] Gunewardena, S.; Archer, W.E.; Sanchez, R.O.: High voltage miniature transformer design. In. Proc. Electrical Insulation Conference and Electrical Manufacturing \& Coil Winding Conference, pp.:141 - 147, 2001.

\section{Nomenclatures:}

$\mu_{\mathrm{H}}$.........Permeability

$\mathrm{B}_{\max }$.......Saturation magnetic induction

$\mathrm{t}_{\mathrm{on}(\max )} \quad .$. Switch maximum on-state time

$\mathrm{t}_{\mathrm{on}(\min )}$..Switch minimum on-state time

$\mathrm{T}_{\mathrm{sw}}$........Switching period

$\mathrm{U}_{\text {Ia }}$.........Amplitude value of isolation transformer primary voltage

$\mathrm{U}_{\text {drf }}$....... Voltage drop in the output rectifier and filter assembly

$\mathrm{U}_{\text {IIa }}$........Amplitude value of isolation transformer secondary voltage

$\mathrm{P}$...........Rated power of the transformer

$\mathrm{k}_{\mathrm{T}}$.........Temperature coefficient of winding resistance

$\mathrm{k}_{\mathrm{U}}$...........Window utilization factor

$\Delta \mathrm{T}$........Transformer temperature rise

A ..........Specific core loss factor 